This information is current as of April 26, 2023.

\title{
Brain Radiation Doses to Patients in an Interventional Neuroradiology Laboratory
}

R.M. Sanchez, E. Vano, J.M. Fernández, M. Moreu and L. Lopez-Ibor

AJNR Am J Neuroradiol 2014, 35 (7) 1276-1280

doi: https://doi.org/10.3174/ajnr.A3884

http://www.ajnr.org/content/35/7/1276 


\title{
Brain Radiation Doses to Patients in an Interventional Neuroradiology Laboratory
}

R.M. Sanchez, E. Vano, J.M. Fernández, M. Moreu, and L. Lopez-Ibor

\begin{abstract}
BACKGROUND AND PURPOSE: In 2011, the International Commission on Radiologic Protection established an absorbed-dose threshold to the brain of 0.5 Gy as likely to produce cerebrovascular disease. In this paper, the authors investigated the brain doses delivered to patients during clinical neuroradiology procedures in a university hospital.
\end{abstract}

MATERIALS AND METHODS: The radiation dose delivered to the brain was investigated in 99 diagnostic and therapeutic interventional neuroradiology procedures. Brain doses were calculated in a mathematic model of an adult standard anthropomorphic phantom by using the technical and radiation dose data of an x-ray biplane system submitted to regular quality controls and calibration programs.

RESULTS: For cerebral embolizations, brain doses resulted in a maximum value of $1.7 \mathrm{~Gy}$, with an average value of 500 mGy. Median and third quartile resulted in 400 and 856 mGy, respectively. For cerebral angiography, the average dose in the brain was 100 mGy.

CONCLUSIONS: This work supports the International Commission on Radiologic Protection recommendation on enhancing optimization when doses to the brain could be higher than $0.5 \mathrm{~Gy}$. Radiation doses should be recorded for all patients and kept as low as reasonably achievable. For pediatric patients and young adults, an individual evaluation of brain doses could be appropriate.

ABBREVIATIONS: $\mathrm{AK}=$ air kerma; $\mathrm{CBCT}=$ conebeam $\mathrm{CT}$; DAP $=$ dose-area product; ICRP $=$ International Commission on Radiologic Protection; INR $=$ interventional neuroradiology

nterventional neuroradiology (INR) provides important benefits to public health, but the use of ionizing radiation has inherent risks that must be evaluated and minimized. The new technology available has the potential to manage radiation risks properly but also allows more complex procedures to be undertaken that may require higher radiation doses for patients and staff. For instance, the inclusion of conebeam CT (CBCT) in modern INR laboratories offers advantages to patients in clinics but may also contribute to increased radiation doses. ${ }^{1,2}$ The brain had traditionally been considered a highly radioresistant organ, but Shimizu et $\mathrm{al}^{3}$ have recently reported a $9 \%$ excess relative risk per Gray for stroke death with brain doses above 0.5 Gy. The International Commission on Radiologic Protection (ICRP) has reviewed

Received October 7, 2013; accepted after revision December 12.

From the Medical Physics Service (R.M.S., E.V., J.M.F.) and Interventional Neuroradiology Department (M.M., L.L.-I.). Instituto de Investigación Sanitaria del Hospital Clínico San Carlos, Madrid, Spain; and Radiology Department (R.M.S., E.V., J.M.F.), Universidad Complutense de Madrid, Medicine Faculty, Madrid, Spain.

Please address correspondence to Roberto Mariano Sanchez, MSc, Hospital Clinico San Carlos, Medical Physics, Madrid 28040, Spain; e-mail: robertomariano. sanchez@salud.madrid.org

http://dx.doi.org/10.3174/ajnr.A3884 recent epidemiologic evidence suggesting that there are some tissuereaction (deterministic) effects, particularly those with very late manifestation, in which threshold doses are or might be lower than previously considered. Although uncertainty remains, medical practitioners should be made aware that the absorbed-dose threshold for circulatory disease may be as low as 0.5 Gy to the brain. ${ }^{4}$ Doses of such magnitude to patients could be reached during some complex interventional procedures; therefore, particular emphasis should be placed on optimization in these circumstances. The ICRP has also stated that in the case of pediatric patients, low-dose irradiation (1-2 Gy) to the developing brain of children can cause long-term cognitive and behavioral defects, and infants treated before 18 months ${ }^{4}$ of age are even more susceptible to cognitive impairment in adult life after exposures to doses of $>0.1 \mathrm{~Gy}$.

Therefore, although these procedures have clear net clinical benefits for patients, it is necessary to know the range of radiation doses delivered to help INR specialists manage radiation risks so that they can provide appropriate information and counseling to their patients. There are few research articles on the topic of patient doses in INR, and the existing articles focus most often on the dose to the skin, the effective dose, or other dose indicators, ${ }^{5-10}$ but they rarely deal with brain doses. 


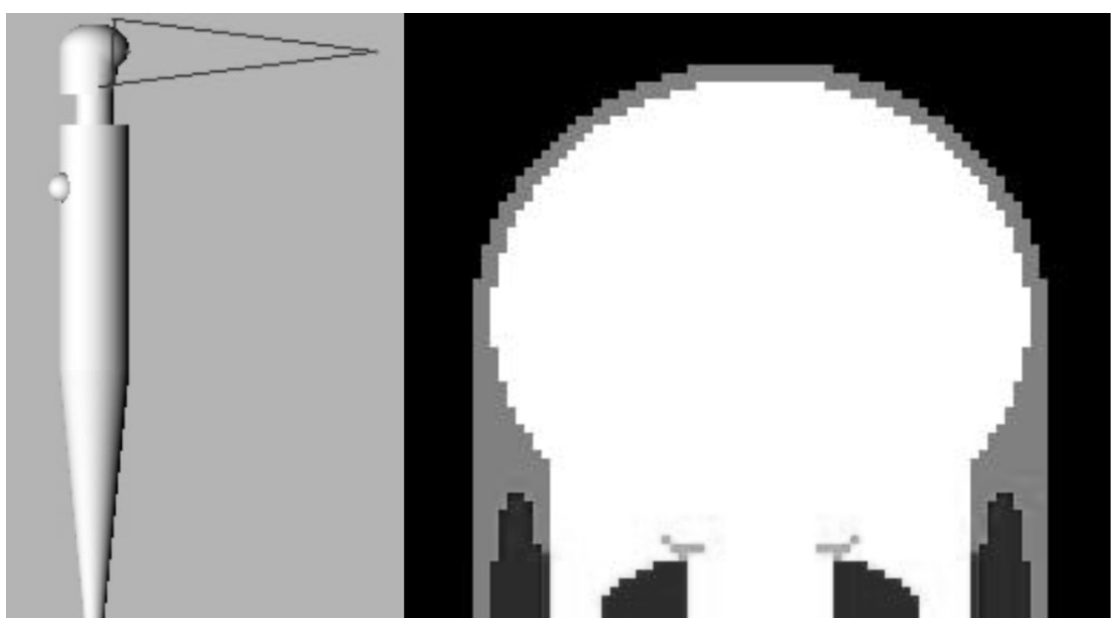

FIG 1. Anthropomorphic phantom used for brain-dose calculation. On the left, a posterior beam projection on the phantom head is shown. On the right, details of the phantom cranium and brain. of CT volumetric image acquisitions (conebeam CT) depending on the CT mode selected, either 313 images (lowdose CT mode) or 622 images (highdose CT) over a $240^{\circ}$ arc rotation with the largest possible beam size. Whatever the CT mode, the system always works with the same technique: $120 \mathrm{kV}, 250$ $\mathrm{mA}, 5 \mathrm{~ms}$, and $0.4-\mathrm{mm} \mathrm{Cu}+2 \mathrm{~mm} \mathrm{Al}$ of added filtration. At the end of all therapeutic procedures at our center, at least 1 CT series, approximately equivalent (in DAP) to 2.7 DSA series or 38 DSA images (cerebral protocol at our center), was acquired in the high-dose mode. For some procedures, a $3 \mathrm{D}$ reconstruction series obtained with rotational acquisition was performed.
Regulations in some countries of the European Union require recording the radiation dose delivered to patients who undergo interventional procedures. In the new Council Directive on protection against ionizing radiation, ${ }^{11}$ the European Commission has stated that "information relating to patient exposure forms part of the report of the medical radiological procedure." Modern INR units do not currently provide radiation doses delivered to patient organs. Instead, they can supply patient dose indicators like kerma area product, also used as dose-area product (DAP), ${ }^{12}$ and air kerma (AK) at the patient entrance reference point, ${ }^{13}$ provided they are suitably validated by a specialist. Because these dose indicators are not generally related directly to patient organ doses, which are the dosimetric quantities relevant to evaluate the biologic effects, the estimation of such doses requires individual calculation by a medical physicist.

In this work, brain doses delivered during INR procedures are reported for a sample of patients at a university hospital. The calculation was performed by using a mathematic model of an anthropomorphic phantom and detailed irradiation parameters recorded from clinical procedures (ie, all fluoroscopy runs and acquisition series). The influence of other variables in brain doses such as the DAP, AK, and beam collimation were also analyzed.

\section{MATERIALS AND METHODS}

Cases of diagnostic cerebral angiography and intracranial embolization were recorded sequentially during a 3-month period. Interventions at carotid and cervical levels were excluded. All procedures were performed in a neuroradiology room equipped with an Allura FD 10/20 (Philips Healthcare, Best, the Netherlands) biplane $\mathrm{x}$-ray unit. The frontal $\mathrm{C}$-arm has a flat detector with a 48-cm diagonal, and the lateral $\mathrm{C}$-arm has a flat detector with a $25-\mathrm{cm}$ diagonal. When locating the patient's head at isocenter, with the image detectors $10 \mathrm{~cm}$ from the patient's head and with no collimation, the frontal detector covers approximately $27 \times 27$ $\mathrm{cm}^{2}$ and the lateral detector, $14 \times 14 \mathrm{~cm}^{2}$. Both $\mathrm{C}$-arms have transmission ionization chambers installed at the $\mathrm{x}$-ray tube exit to monitor the DAP delivered to patients, which is included in the patient dose reports. In most procedures, digital subtraction angiography series are acquired at 2 images per second during the first 10 seconds and at 1 image per second during the rest of the time. The system has the ability to perform 2 types
The program PCXMC 2.0 Rotation (http://www.stuk.fi/sateilynhyodyntaminen/ohjelmat/PCXMC/en_GB/pcxmc/) ${ }^{14}$ was used to calculate brain doses. This program calculates organ-equivalent doses and effective dose in a mathematic model of an anthropomorphic phantom of different ages and sizes. The program performs Monte Carlo simulations throughout the anthropomorphic phantom by using patient dose indicators (DAP, incident air kerma, and so forth) and geometric and physical parameters of the different $\mathrm{x}$-ray projections (kilovolt, added filtration, $\mathrm{C}$-arm angulation, and so forth). All calculations were performed on the standard phantom (Fig 1) corresponding to an adult measuring $179 \mathrm{~cm}$ and weighing $73 \mathrm{~kg}$ and containing the anatomic data based on the mathematic model of Cristy and Eckerman. ${ }^{15}$

Detailed information of the geometric and physical parameters was recorded for each beam projection at series level on the $\mathrm{x}$-ray system and extracted with the help of Philips support engineers. This information, now directly available from the DICOM Radiation Dose Structured Reports, provided the $\mathrm{x}$-ray system has been upgraded to allow this functionality, includes generator and $\mathrm{x}$-ray tube setting potential (kilovolt), tube current (milliampere), pulse duration (milliseconds), added filtration, beam collimation, and C-arm angulations per projection for all fluoroscopy runs and DSA acquisition series. DAP and AK were also provided for each projection, then verified and corrected by a medical physicist, taking into account the couch and mattress attenuation in the frontal C-arm and the calibration of the DAP meter.

For the calculation of brain doses, DAP was used. The Philips Allura FD 20/10 has distances from the focus to rotation axis of 81 and $76.5 \mathrm{~cm}$ for the frontal and lateral C-arms, respectively. All data used to calculate patient doses were obtained from the data recorded at the radiation unit during clinical procedures, with the exception of the positioning of the patient whose brain is to be centered at the $\mathrm{C}$-arm isocenter (a precondition of the conebeam $\mathrm{CT}$ acquisitions). The $\mathrm{x}$-ray beam characteristics were introduced in the software by using the kilovolt and added filtration used on each beam projection. A fixed inherent filtration of $2.5 \mathrm{~mm} \mathrm{Al}$ and anodic angles of $11^{\circ}$ and $9^{\circ}$ for the frontal and lateral $\mathrm{x}$-ray tubes, 
respectively, were also used. Wedge compensation filters were not used in our center for these procedures.

The brain doses calculated were compared with patient dose indicators (DAP and AK) and beam collimation.

\section{RESULTS}

Of 99 procedures recorded, 61 were cerebral angiographies and 38 were cerebral embolizations. On average, the diagnostic cases have lower DAP $\left(64.5 \mathrm{~Gy} \cdot \mathrm{cm}^{2}\right)$ than the therapeutic ones $(230$ $\mathrm{Gy} \cdot \mathrm{cm}^{2}$ ). The average number of projections (fluoroscopy runs and DSA acquisitions) was 49 for cerebral angiographies and 159 for therapeutics. A total of 9031 beam projections were processed for the brain-dose calculations. The main statistical param-

Table 1: Main statistics for brain doses (in mGy) for cerebral angiography and embolization

\begin{tabular}{lcc}
\hline & $\begin{array}{c}\text { Cerebral } \\
\text { Angiography }\end{array}$ & $\begin{array}{c}\text { Cerebral } \\
\text { Embolization }\end{array}$ \\
\hline No. & 61 & 38 \\
Minimum & 26 & 155 \\
Maximum & 568 & 1678 \\
Mean & 100 & 500 \\
SD & 92 & 346 \\
lst Quartile & 45 & 250 \\
Median & 73 & 397 \\
3rd Quartile & 123 & 645 \\
\hline
\end{tabular}

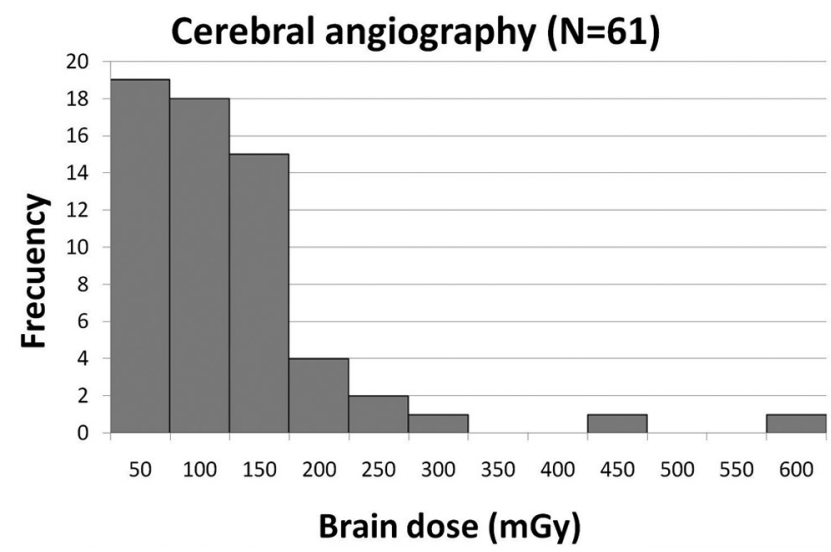

eters for brain doses are presented in Table 1. Figure 2 shows the frequency histograms. Thirty-four percent of therapeutic procedures had brain doses of $\geq 500 \mathrm{mGy}$. The total number of procedures $(n=99)$ corresponds to 81 patients because 14 patients underwent $>1$ procedure in the 3 months. If one takes into account the repetition of procedures, of the 38 patients with at least 1 therapeutic procedure, the fraction of patients with brain doses of $>500 \mathrm{mGy}$ is $40 \%$, and with doses of $>1000 \mathrm{mGy}, 19 \%$. Ten of 15 patients with brain doses greater than $500 \mathrm{mGy}$ underwent $>1$ procedure.

Figure 3 presents brain doses versus DAP and AK. Lines show Pearson correlation coefficients of $>0.9$ for both variables. Figure 4 shows the brain dose relative to the AK ratio represented versus the weighted average field size for each procedure. The average field size for each patient is weighted by the DAP of each projection. An average difference of a factor of 2 can be observed in brain doses between the greatest and smallest field sizes.

The dose delivered during a CBCT series was $23.5 \mathrm{~Gy} \cdot \mathrm{cm}^{2}$ in terms of DAP for the high-dose CBCT, which yielded a calculated $32 \mathrm{mGy}$ to the brain and $1.65 \mathrm{mSv}$ of effective dose (ICRP-103). ${ }^{16}$ In the case of the low-dose CBCT, which uses half the projections with the same settings, brain and effective doses were also halved.

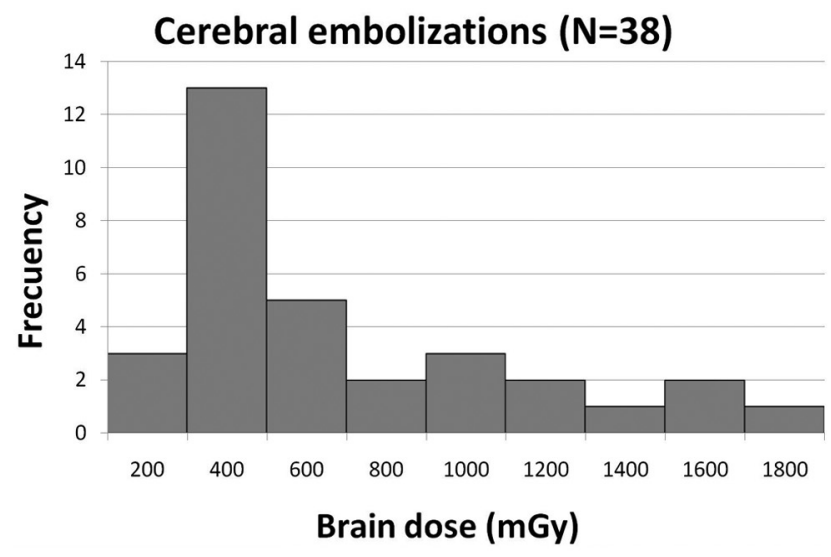

FIG 2. Frequency histogram with brain doses for cerebral angiography and embolization. Average brain dose resulted in $100 \mathrm{mGy}$ for cerebral angiography and $500 \mathrm{mGy}$ for embolizations.

Brain dose vs. DAP

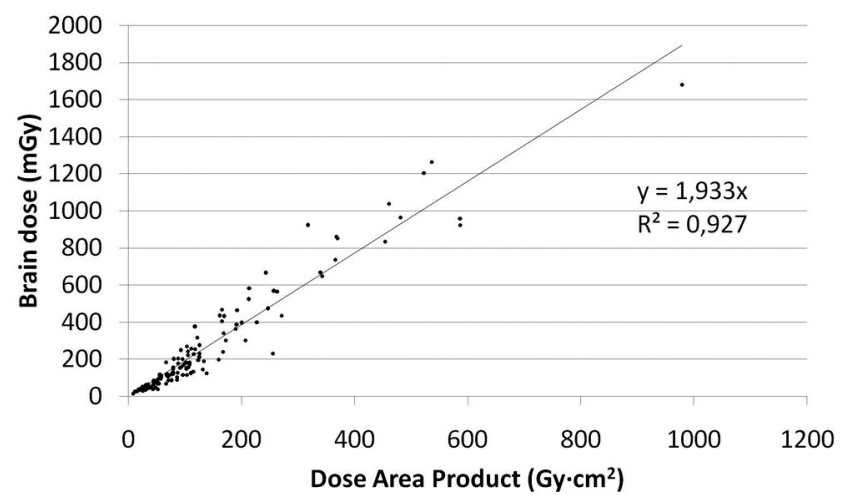

Brain dose vs. AK

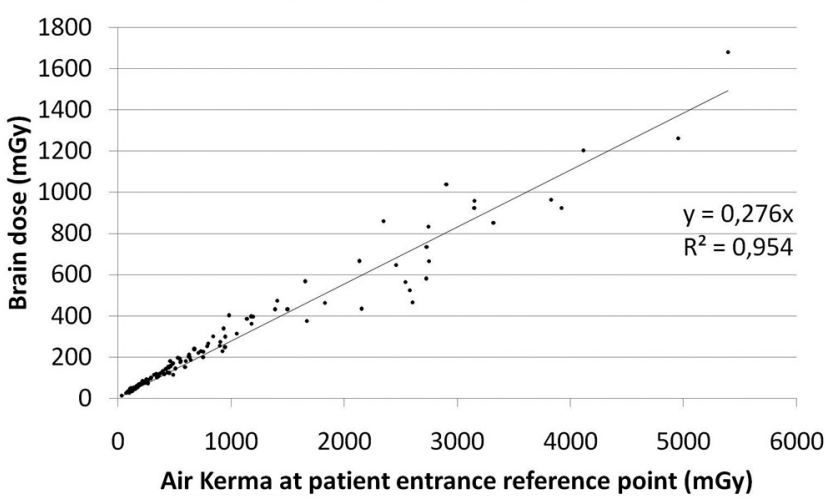

FIG 3. The brain dose for the 99 procedures is represented versus the 2 main dose indicators provided by modern interventional $x$-ray units, DAP and AK. Linear regression presents good correlation. 


\section{DISCUSSION}

Doses as high as 1.7 Gy have been delivered to the brain during a therapeutic procedure in the sample of procedures included in this work. In 34\% of these procedures in our institution, the dose exceeded $500 \mathrm{mGy}$ (ie, the new dose threshold set by the ICRP). Given that, in some cases, several procedures are performed on the same patient, $40 \%$ of the patients in the sample investigated received $>500 \mathrm{mGy}$ in the brain. In diagnostic procedures, exceeding this threshold dose is unlikely. The ICRP has fixed the dose threshold when the probability of radiation injury is $>1 \%$. In the case of death from stroke, the excess of relative risk reported by Shimizu et $\mathrm{al}^{3}$ is $3 \%$ between 0 and $0.5 \mathrm{~Gy}$ and approximately $11 \%$ for $1.5 \mathrm{~Gy}$. Most of these therapeutic procedures are clearly justified for clinical reasons (they are life-saving), more particularly when they are expected to prevent stroke death, but the radiation doses to the brain reported in this article show that optimization, as recommended by the ICRP, is essential, especially in young patients with long life expectancies after interventions.

Figure 5 shows age histograms for the sample of patients investigated. Values for mean, median, and first quartile are quite similar for angiographies and embolizations. The average age of patients was 56 years, with a median of 60 years and a 25 th percentile of 47 years; in both types of procedures, there was 1 patient younger than 15 years. Therefore, in such procedures, radiation

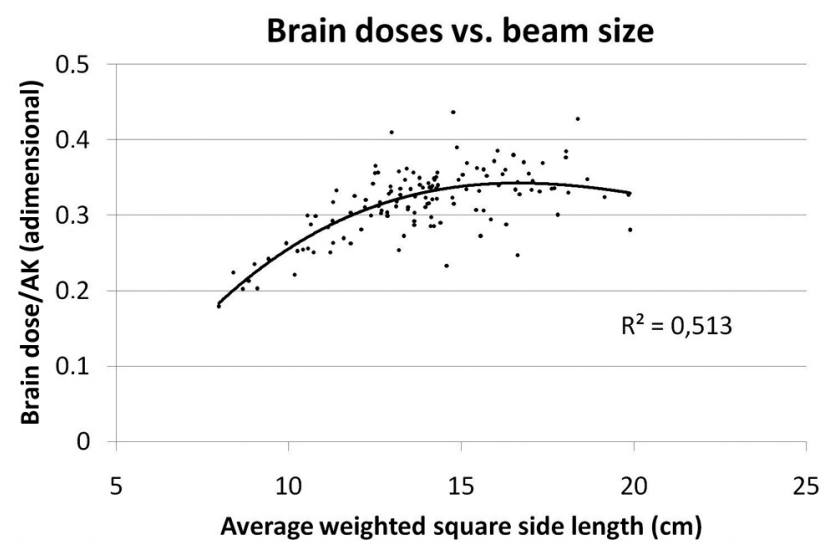

FIG 4. For the 99 procedures, the brain dose is related to the average weighted field size. In both images, one can appreciate how brain doses are almost doubled when the field size rises from 8 to $15 \mathrm{~cm}$ or more.

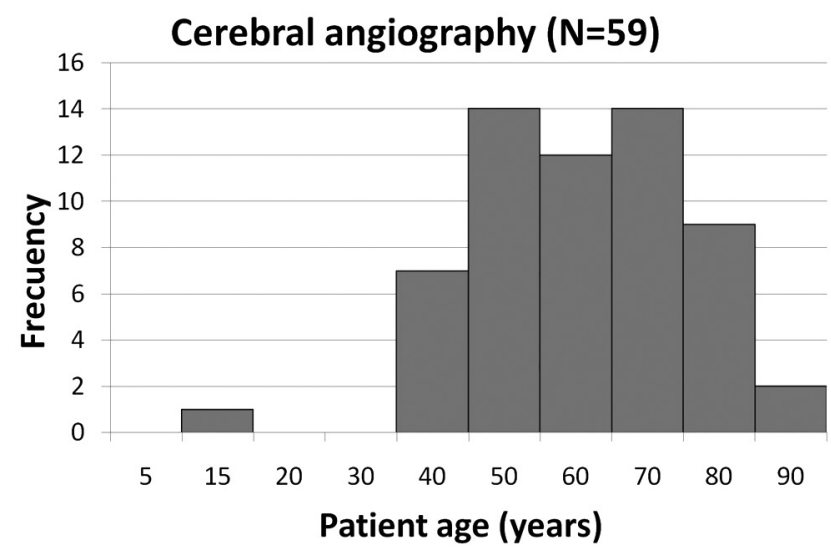

FIG 5. Age histograms for the sample of patients in this survey. risks must be taken into account, especially with pediatric patients and young adults.

When we compared scientific articles already published, we found that most publications reported patient dose indicators like DAP, AK, or skin dose. Miller et $\mathrm{al}^{5}$ reported DAP in a multicenter survey in the United States, with an average DAP of $320 \mathrm{~Gy} \cdot \mathrm{cm}^{2}$ for embolizations, $39 \%$ higher than in this work $\left(230 \mathrm{~Gy} \cdot \mathrm{cm}^{2}\right)$. Sandborg et $\mathrm{al}^{8}$ investigated skin doses to the head during INR cases and reported an average DAP for embolization of $189 \mathrm{~Gy} \cdot$ $\mathrm{cm}^{2}$. Thierry-Chef et $\mathrm{al}^{7}$ investigated brain doses in a sample of 49 pediatric patients undergoing intracranial embolizations. Depending on the beam collimation (not reported in the article), the average brain dose could range from 68 to $490 \mathrm{mGy}$ for the high and low levels of collimation, respectively. In this survey, mainly focused on adult patients, the average brain dose was $500 \mathrm{mGy}$.

A good correlation was shown between DAP and AK in the sample investigated, probably because of the simple irradiation geometry of the cranial procedures and the level of collimation. These findings make it possible to estimate brain doses with reasonable accuracy if the dose indicators (DAP and KA), available in most modern interventional x-ray units, are properly calibrated. The variability found in the literature on DAP values and brain doses indicates that a diligent mode of operation is essential to optimize radiation doses. Figure 3 shows that if one uses a beam size as small as possible, important dose reductions can be achieved and that when one uses $\mathrm{x}$-ray beams with high filtration, brain doses can be reduced drastically during fluoroscopy runs and DSA acquisitions.

The dose delivered to the brain during a high-dose CBCT resulted in $32 \mathrm{mGy}, 32 \%$ of the mean brain dose for a diagnostic procedure. In embolizations, with a higher mean dose (500 mGy), 1 high-dose CBCT represented 6\% of the total brain dose. Other studies ${ }^{17,18}$ have reported lower values of CBCT doses in the head as shown in Table 2 . These lower values are mainly consequences of the use of automated exposure controls to adjust the dose required to a minimum for each projection and, in some cases, of a lower number of projections. However, the ratio effective dose over the DAP is of the same order of magnitude (Table 2). Koyama et al, ${ }^{19}$ who measured doses in a phantom with a protocol but without automated exposure control and similar kilovolt and milliampere-second settings, reported brain doses similar to those in this study.

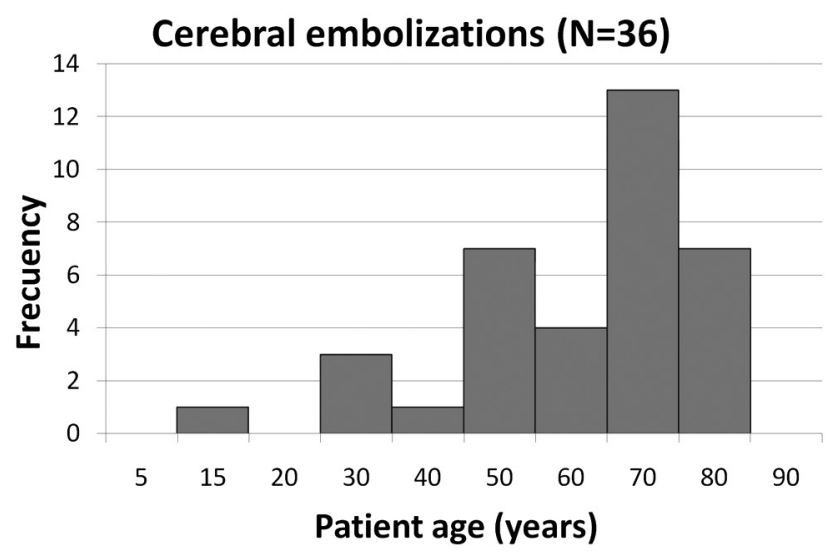


Table 2: Comparison of dose parameters in CBCT with other authors ${ }^{\mathrm{a}}$

\begin{tabular}{lcccc}
\hline & $\begin{array}{c}\text { DAP } \\
\left(\mathrm{Gy} \cdot \mathrm{cm}^{2}\right)\end{array}$ & $\begin{array}{c}\text { Brain } \\
\text { Equivalent } \\
\text { Dose }(\mathrm{mGy})\end{array}$ & $\begin{array}{c}\text { ED } \\
\text { ICRP-103 } \\
(\mathbf{m S v})\end{array}$ & $\begin{array}{c}\text { ED/DAP } \\
\left(\mathbf{m S v} /\left[\mathrm{Gy} \cdot \mathbf{c m}^{2}\right]\right)\end{array}$ \\
\hline $\begin{array}{c}\text { Koyama et al } \\
(2010)^{19}\end{array}$ & - & $14-37$ & $0.47-1.2$ & - \\
${\text { Kim et al }(2012)^{17}}^{17}$ & $5.99-9.61$ & $5-6$ & $0.38-0.87$ & $0.06-0.09$ \\
Bai et al $(2013)^{18}$ & $9.4 \pm 2$ & 6 & $0.30 \pm 0.08$ & $0.03-0.035$ \\
This study & $11.75-23.5$ & $16-32$ & $0.83-1.6$ & 0.09 \\
\hline
\end{tabular}

Note:-ED indicates effective dose estimated with the parameters from the document ICRP-103

a Kim et al and Koyama et al provide a range of dose estimations for several situations (kilovolt, collimation, or gantry tilt). Bai et al provide mean values \pm SD for a sample of patients, except for the brain dose, for which they provide a phantom estimation.

The approach and process for calculating brain doses have some limitations. It was assumed that all fluoroscopic series were delivered to the brain, when, in fact, most procedures start at the femoral artery and a small part of the initial fluoroscopy could be made in the abdomen. Another source of inaccuracies could result from taking for granted that the patient brain is always centered at the $\mathrm{C}$-arm isocenter, which happens not to be the case in some parts of the procedure. Therefore, in some cases with a large fluoroscopy time at leg or aortic levels and in cases in which the lesion is located at the brain peripheral region, a small overestimation of brain doses may be observed. Our approach could, therefore, be considered as a conservative estimation of brain doses in INR procedures.

\section{CONCLUSIONS}

The dose delivered to the brain of patients undergoing interventional neuroradiology procedures may be relevant enough to produce radiation side effects and must be minimized as much as possible. The radiation dose to patients should be monitored for all interventional procedures by using the standardized dose indicators DAP and AK and should be included in the patient clinical report. For interventions of high complexity and high radiation doses, an individual dose calculation to some sensitive organs/tissues like the brain, eye lenses, or skin may be needed, especially for pediatric patients and young adults and patients likely to undergo repeat procedures. To optimize the procedures and minimize patient doses, one must reduce the number of series, the number of frames per series, and the frame rates to the minimum necessary; collimate the radiation beam to the region of interest; reduce the detector-to-patient distance; and use $\mathrm{x}$-ray beams with high-added filtration. It is also important to have a quality-assurance program to ensure that the $\mathrm{x}$-ray dose rate remains within acceptable values.

\section{ACKNOWLEDGMENTS}

The authors thank Philips Medical Systems for their assistance in recording all the physical parameters of the x-ray system.

Disclosures: Manuel Moreu—UNRELATED: Grants/Grants Pending: Fundación para la Investigación Biomédica del Hospital Clínico San Carlos.

\section{REFERENCES}

1. Berris T, Gupta R, Rehani MM. Radiation dose from cone-beam CT in neuroradiology applications. AJR Am J Roentgenol 2013;200: 755-61

2. Kyriakou Y, Richter G, Dölfler A, et al. Neuroradiologic applications with routine $\mathrm{C}$-arm flat panel detector CT: evaluation of patient dose measurements. AJNR Am J Neuroradiol 2008;29:1930-36

3. Shimizu Y, Kodama K, Nishi N, et al. Radiation exposure and circulatory disease risk: Hiroshima and Nagasaki atomic bomb survivor data, 1950-2003. BMJ 2010;340:b5349

4. ICRP Statement on Tissue Reactions/Early and Late Effects of Radiation in Normal Tissues and Organs - Threshold Doses for Tissue Reactions in a Radiation Protection Context. ICRP Publication 118. Ann. ICRP 41(1/2) 2012

5. Miller DL, Balter S, Cole P, et al. Radiation Doses In Interventional Radiology procedures: the RAD-IR Study. J Vasc Interv Radiol 2003;14:977-90

6. Struelens L, Vanhavere F, Bosmans H, et al. Skin dose measurement on patients for diagnostic and interventional neuroradiology: a multicentre study. Radiat Prot Dosimetry 2005;114:143-46

7. Thierry-Chef I, Simon SL, Land CE, et al. Radiation dose to the brain and subsequent risk of developing brain tumors in pediatric patients undergoing interventional neuroradiology procedures. $R a$ diat Res 2008;170:553-65

8. Sandborg M, Rossitti R, Pettersson H. Local skin and eye lens equivalent doses in interventional neuroradiology. Eur Radiol 2010; 20:725-33

9. Kien N, Rehel JL, Étard C, et al. Patient dose during interventional neuroradiology procedures: results from a multi-center study [in French]. J Radiol 2011;92:1101-12

10. Vano E, Fernandez JM, Sanchez RM, et al. Patient radiation dose management in the follow-up of potential skin injures in neuroradiology. AJNR Am J Neuroradiol 2013;34:277-82

11. European Commission. COUNCIL DIRECTIVE 2013/59/EURATOM of 5 December 2013 laying down basic safety standards for protection against the dangers arising from exposure to ionising radiation, and repealing Directives 89/618/Euratom, 90/641/Euratom, 96/29/Euratom, 97/43/Euratom and 2003/122/Euratom. Available at http://eurlex.europa.eu/JOHtml.do?uri=OJ:L:2014:013:SOM:EN:HTML. Accessed February 5, 2014.

12. International Commission on Radiation Units and Measurements. ICRU report 74: patient dosimetry for $X$ rays used in medical imaging. Journal of the International Commission on Radiation Units and Measurements 2005:5

13. International Electrotechnical Commission. Medical electrical equipment. Part 2-43. Particular requirements for the safety of X-ray equipment for interventional procedures. Report IEC 60601-2-43 2010. Geneva, Switzerland.

14. Tapiovaara M, Siiskonen T. PCXMC, A Monte Carlo program for calculating patient doses in medical $x$-ray examinations. 2nd ed. Helsinki: STUK-Radiation and Nuclear Safety Authority of Finland; 2008

15. Cristy M, Eckerman KF. Specific absorbed fractions of energy at various ages from internal photon sources. I. Methods. Report ORNL/TM-8381/ V1. Oak Ridge, Tennessee: Oak Ridge National Laboratory; 1987

16. ICRP 2007. The 2007 Recommendations of the International Commission on Radiological Protection. Ann. ICRP Publication 103. ICRP 37 (2-4)

17. Kim S, Sopko D, Toncheva G, et al. Radiation dose from 3D rotational X-ray imaging: organ and effective dose with conversion factors. Radiat Prot Dosimetry 2012;150:50-54

18. Bai M, Liu X, Liu B.. Effective patient dose during neuroradiological C-arm CT procedures. Diagn Interv Radiol 2013;19:29-32

19. Koyama S, Aoyama T, Oda N, et al. Radiation dose evaluation in tomosynthesis and C-arm cone-beam CT examination with an anthropomorphic phantom. Med Phys 2010;37:4298-306 